\title{
Circumcision Revision in Male Children
}

\author{
Mohammed A. Al-Ghazo, Kamal E. Banihani \\ King Abdullah University Hospital, Faculty of Medicine, Jordan University of Science \& \\ Technology (JUST), Irbid, Jordan
}

\begin{abstract}
Objective: To determine indications for circumcision revision and to identify the specialty of the person who performed unsatisfactory primary circumcision.

Materials and Methods: The authors reviewed medical records of 52 cases that underwent circumcision revision over a 6year period (1998 to 2004). Sleeve surgical technique was used for revision in patients with redundant foreskin or concealed penis, penoplasty for partial or complete degloving of the penis and meatotomy for external meatal stenosis. The mean age of children was 32 months (range 6 months to 9 years).

Results: Most of unsatisfactory primary circumcisions $(86.7 \%)$ were performed by laymen. All patients who underwent circumcision revision had good to excellent cosmetic results.

Conclusion: Primary circumcision performed by laymen carry a high complication rate and serious complications may occur. A period of training and direct supervision by physicians is required before allowing laymen to perform circumcision independently.
\end{abstract}

Key words: penis; circumcision; surgical injuries; reoperation

Int Braz J Urol. 2006; 32: 454-8

\section{INTRODUCTION}

Circumcision is a surgical procedure performed for centuries for medical, religious and several other reasons. Circumcision is the most common surgical procedure performed in boys among the Islamic community around the world (1). It has been reported that $77 \%$ of the male population born in the United States has been circumcised (2). Children undergoing circumcision certainly are at a risk for complications (3).

Neonatal circumcision in Jordan remains a frequent surgical procedure that is performed by a variety of practitioners, including urologists, family practitioners, obstetricians, general surgeons and Mohels. Although the procedure is performed by multiple specialists, overall results are excellent (4). Sometimes the parents are unsatisfied with the results of primary circumcision due to redundant foreskin, concealed penis, excessive excision of penile skin or other complications. Many of these children are referred to urologists for circumcision revision.

A 6-year consecutive series of male children who underwent circumcision revision was analyzed to determine the indications for revision, to identify the specialty of the person who performed the unsatisfactory circumcision and to recommend the laymen the best way to decrease the complication rate of circumcision. 


\section{MATERIALS AND METHODS}

We reviewed the medical records of 52 patients who were referred to the urological department in the period between 1998 and 2004 for revision of circumcision. Indications for revision of circumcision are shown in Table-1.

The specialty of persons who performed the primary circumcision of these patients was identified. In nine cases additional operations were performed at the time of circumcision revision, including herniotomy for hydrocele $(n=4)$, herniotomy for inguinal hernia $(n=2)$ and orchiopexy $(n=3)$. Other penile conditions requiring surgical repair were noted in 17 cases, including urethrocutaneous fistula, penile sebaceous cyst, preputial-glanular bridges, and meatal stenosis. In 14 cases, the foreskin was redundant, in seven cases the penis was concealed by a circumferential scar of primary circumcision as shown in Figure-1.

Only in 7 cases primary circumcision was performed by physicians (pediatric surgeons, gynecologists and pediatricians), while the other cases were performed by laymen ( $86.5 \%)$.

Revision was performed under general anesthesia in all patients. All patients remained in the hospital overnight after revision of circumcision. Intravenous prophylactic antibiotics for three doses were administered to all patients; one dose at the time of induction of anesthesia followed by two doses postoperatively.

Table 1 - Causes of circumcision revision.

\begin{tabular}{lc}
\hline Cause & N patients \\
\hline Redundant foreskin & 14 \\
External meatal stenosis & 9 \\
Circumcision for patients with hypospadias & 8 \\
Concealed penis & 7 \\
Complete or partial degloving of penis & 5 \\
Urethra-cutaneous fistula & 4 \\
Preputial-glanular bridges & 3 \\
Penile sebaceous cyst & 1 \\
Buried penis & 1 \\
Total & 52 \\
\hline
\end{tabular}

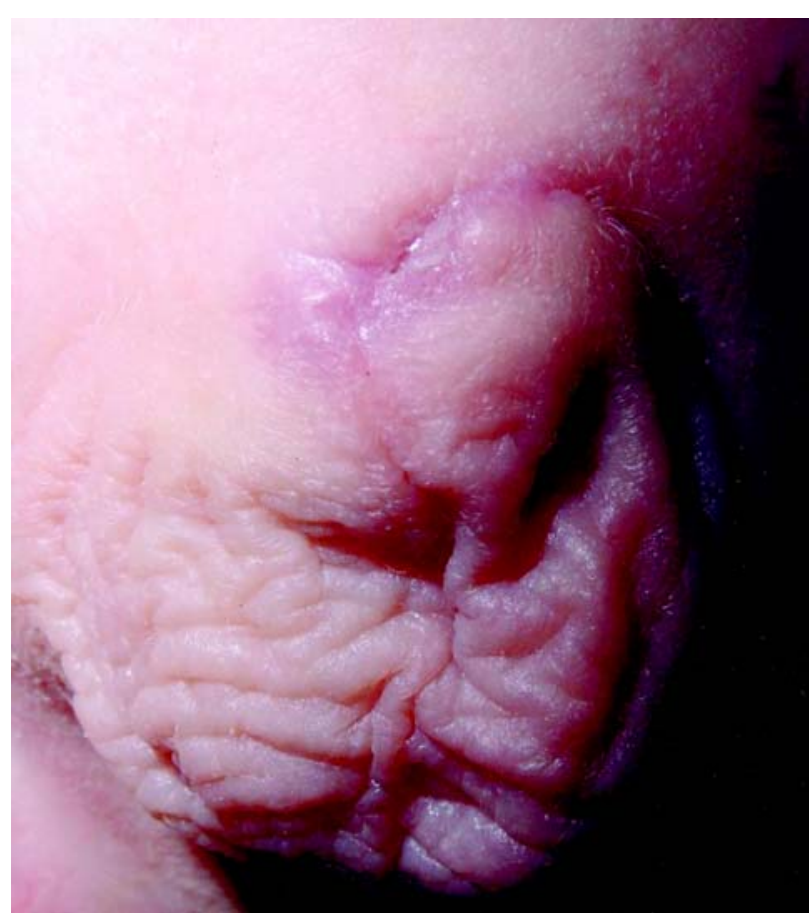

Figure 1 - Concealed penis after circumcision.

Conventional sleeve technique was the surgical procedure used for circumcision revision in patients with redundant penile skin or concealed penis, while penoplasty was performed in patients with complete or partial degloving of the penis, using scrotal skin flaps. External meatotomy was performed for patients with external meatal stenosis. Eight patients with hypospadias were circumcised by laymen. All these patients had distal type pf hypospadias and were treated by tubularized incised-plate urethroplasty (TIP). Patients with urethrocutaneous fistula were treated by layered repair of the fistula.

\section{RESULTS}

From August 1998 to August 2004, 52 children ranging in age from 6 months to nine years (mean 32 months) underwent circumcision revision. On the basis of surgeon evaluation of the postoperative appearance and the satisfaction of patients' family, all patients had good to excellent results. 
Penoplasty for complete or partial penile skin degloving which was performed in five cases showed good cosmetic results. All patients with concealed penis and redundant skin (21 cases) who were treated by conventional sleeve technique showed excellent cosmetic results except one patient who developed superficial wound infection, which was treated by antibiotics and dressings. External meatotomy was performed for children with meatal stenosis with good results.

Unfortunately, the overall complication rate for circumcision could not be calculated because most of them were performed by laymen at home. Analyzing the rate and severity of postcircumcision complications in patients who required revision showed that complications in the hand of trained physicians were all less severe as opposed to laymen. Redundant skin ( 6 cases), partial degloving of the penis ( 1 case).

Analyzing the technique used for primary circumcision, we found that the physicians used conventional sleeve technique, while laymen used electrocautery to cut the prepuce without adequate dissection of the prepuce from the glans and without using sutures to oppose the cut edges of the prepuce.

Patients with hypospadias treated by TIP showed good results except in two patients who developed urethrocutaneous fistula which were treated successfully through the layered technique. Layered repair technique used for urethrocutaneous fistula following circumcision resulted in complete healing in three patients, while the fourth patient developed a pinpoint fistula and meatal stenosis, which were corrected by a second operation.

\section{COMMENTS}

Although circumcision is a frequent and simple operation. It may lead to uncommon complications due to lack of experience and poor technique. When circumcisions are performed by physicians an overall $0.2 \%$ of circumcised children have complications, and a complication can be expected in 1 out of 476 circumcisions performed (5). Other series reported a complication rate of $3.1 \%$ (6).
Although neonatal circumcision is common in Jordan as it is performed for religious reasons, mass circumcision is not common in our country. Mass circumcision is more common in Turkey and the Gulf states. Mass circumcision usually carries significantly greater risk and should be prevented (7).

Traditional (medically untrained) circumcisers were responsible for $85 \%$ of the complications and almost all the disastrous ones in one series (7). Cases of complications of the primary circumcision referred to our department for revision of circumcision were most commonly performed by laymen (persons who are medically untrained) $(86.5 \%)$. When laymen perform circumcision they usually do not inspect the penis carefully prior to circumcision, and they do not practice careful visualization during all aspects of the procedure. They also do not postpone the circumcision when they notice a penile abnormality.

In the literature, only few reported series addressed circumcision revision $(4,8)$. Similar to previous reported series, redundant skin was the most common reason for revision in our series. It was reported that there is no improvement in the appearance of the redundant foreskin with age (9). For this reason, we recommend early revision for redundant foreskin.

Posthitis associated with redundant foreskin was found in 2 cases (14.3\%) in our series. In reported series, the rate of this complication ranged from zero to $15.2 \%(4,8)$. In the face of serious complications following primary circumcision performed by laymen, a period of training and direct supervision of the procedure by physicians should be a mandatory requirement, and then, when considered competent by physician supervisor, laymen may perform circumcision independently.

Meatal stenosis is an under recognized complication of circumcision $(10,11)$. Post circumcision meatal stenosis occurs usually as a result of fibrosis and scaring (11). Van Howe reported that meatal stenosis may be the most common complication following circumcision. He also reported that the ratio of circumcised boys to non-circumcised provided $80 \%$ power to demonstrate a $21.4 \%$ difference in the incidence of meatal stenosis between circumcised and non-circumcised Tanner I boys 3 years and older (12). 
In our series, nine patients had external meatal stenosis most likely secondary to circumcision.

Seven of our patients had concealed penis. Circumcision was reported to be an iatrogenic cause in etiology of a concealed penis $(13,14)$. It usually results from lack of experience and poor technique (13).

Whilst urinary retention is a well recognized complication of circumcision, there was one report of significant obstructive uropathy and renal impairment due to circumcision (15). None of our patients had an obstructive uropathy. The cause of the obstructive uropathy is the dressing and the edema of the glans (15).

Nine of our patients had either buried penis $(\mathrm{n}=1)$ or hypospadias $(\mathrm{n}=8)$ prior to circumcision. The buried penis is a rare congenital anomaly in which a circumcision can result in deformity and functional disorder of the penis (16). Circumcision should be avoided in an infant with a definite diagnosis of buried penis or hypospadias $(17,18)$. Our patients with these anomalies were circumcised by laymen who lack the knowledge of complications of circumcision in these cases.

Urethrocutaneous fistula, ischemic glans penis and amputation of the glans penis are serious complications of circumcision, which had been reported before (10,19-21).

Urethrocutaneous fistula is a well-known complication of circumcision. Considering the high rate of circumcision, the reported incidence of urethrocutaneous fistula is relatively low (22). The cause of fistula following circumcision is either surgical trauma or deeply placed suture at frenulum in an attempt to control bleeding, which results in a strangulation and necrosis of part of the urethral wall (22). In our series, four patients had urethra-cutaneous fistula as a complication of circumcision performed by laymen. All these fistulae appeared in early postcircumcision. Urethrocutaneous fistula following circumcision in all patients in this series was distal similar to reported series (23).

Routine circumcision of infants even those with congenital hypospadias, still take place in some parts of the world. Hypospadias repair in such patients is difficult (24). Therefore, different operative techniques were reported for treatment of such pa- tients, such as one-stage transverse penile cutaneous island flap (24), T flap hypospadias repair (25) and TIP urethroplasty (26). In this series sufficient outcomes were obtained in six of the eight $(75 \%)$ circumcised patients with hypospadias repaired by TIP urethroplasty which is similar to reported results (26).

\section{CONCLUSION}

Primary circumcision performed by medically untrained laymen carry a high complication rate and a serious complication may occur. A period of training and direct supervision by physicians is required before allowing laymen to perform circumcision independently. Circumcision revision performed by urologists ends up in good to excellent results.

\section{CONFLICT OF INTEREST}

None declared.

\section{REFERENCES}

1. Akoz T, Erdogan B, Gorgu M, Aslan G, Altintas H: Unusual complications of circumcision. Plast Reconstr Surg. 1998; 101: 1915-8.

2. Laumann EO, Masi CM, Zuckerman EW: Circumcision in the United States. Prevalence, prophylactic effects, and sexual practice. JAMA. 1997; 277: 10527.

3. Patel HI, Moriarty KP, Brisson PA, Feins NR: Genitourinary injuries in the newborn. J Pediatr Surg. 2001; 36: 235-9.

4. Brisson PA, Patel HI, Feins NR: Revision of circumcision in children: Report of 56 cases. J Pediatr Surg. 2002; 37: 1343-6.

5. Christakis DA, Harvey E, Zerr DM, Feudtner C, Wright JA, Connell FA: A trade-off analysis of routine newborn circumcision. Pediatrics. 2000; 105: 246-9.

6. O'Brien TR, Calle EE, Poole WK: Incidence of neonatal circumcision in Atlanta, 1985-1986. South Med J. 1995; 88: 411-5.

7. Ozdemir E: Significantly increased complication risks with mass circumcisions. Br J Urol. 1997; 80: 136-9. 
8. Redman JF: Circumcision revision in prepubertal boys: analysis of a 2-year experience and description of a technique. J Urol. 1995; 153: 180-2.

9. Breuer GS, Walfisch S: Circumcision complications and indications for ritual recircumcision-clinical experience and review of the literature. Isr J Med Sci. 1987; 23: 252-6.

10. Ahmed A, Mbibi NH, Dawam D, Kalayi GD: Complications of traditional male circumcision. Ann Trop Paediatr. 1999; 19: 113-7.

11. Upadhyay V, Hammodat HM, Pease PW: Post circumcision meatal stenosis: 12 years' experience. N Z Med J. 1998; 111: 57-8.

12. Van Howe RS: Incidence of meatal stenosis following neonatal circumcision in a primary care setting. Clin Pediatr (Phila). 2006; 45: 49-54.

13. Esen AA, Aslan G, Kazimoglu H, Arslan D, Celebi I: Concealed penis: rare complication of circumcision. Urol Int. 2001; 66: 117-8.

14. Yildirim S, Akoz T, Akan M: A rare complication of circumcision: concealed penis. Plast Reconstr Surg. 2000; 106: 1662-3.

15. Craig JC, Grigor WG, Knight JF: Acute obstructive uropathy - a rare complication of circumcision. Eur J Pediatr. 1994; 153: 369-71.

16. van der Zee JA, Hage JJ, Groen JM, Bouman FG: A serious complication of ritual circumcision of a 'buried' penis. Ned Tijdschr Geneeskd. 1991; 135: 16046.

17. Milos MF: Significantly increased complication risks with mass circumcisions. Br J Urol. 1998; 81: 341.
18. Brisson P, Patel H, Chan M, Feins N: Penoplasty for buried penis in children: report of 50 cases. J Pediatr Surg. 2001; 36: 421-5.

19. Coskunfirat OK, Sayilkan S, Velidedeoglu H: Glans and penile skin amputation as a complication of circumcision. Ann Plast Surg. 1999; 43: 457.

20. Tzeng YS, Tang SH, Meng E, Lin TF, Sun GH: Ischemic glans penis after circumcision. Asian J Androl. 2004; 6: 161-3.

21. Neulander E, Walfisch S, Kaneti J: Amputation of distal penile glans during neonatal ritual circumcisiona rare complication. Br J Urol. 1996; 77: 924-5.

22. Yazici M, Etensel B, Gursoy H: A very late onset urethral fistula coexisting with skin bridge after neonatal circumcision: a case report. J Pediatr Surg. 2003; 38: 642-3.

23. Guralnick ML, al-Shammari A, Williot PE, Leonard MP: Outcome of hypospadias repair using the tubularized, incised plate urethroplasty. Can J Urol. 2000; 7: 986-91.

24. Ntia IO, Osegbe DN, Amaku EO: One-stage penile cutaneous island flap repair for hypospadias in circumcized patients. Eur Urol. 1988; 14: 450-3.

25. Bang RL, Ebrahim MK, Lari AR: T flap hypospadias repair in circumcised patients. Br J Plast Surg. 1993; 46: 164-7.

26. Cakan M, Yalcinkaya F, Demirel F, Aldemir M, Altug $\mathrm{U}$ : The midterm success rates of tubularized incised plate urethroplasty in reoperative patients with distal or midpenile hypospadias. Pediatr Surg Int. 2005; 21 : 973-6.

Correspondence address:

Dr. Mohammed A. Al-Ghazo

Assistant Professor of Urology

Jordan University of Science \& Technology

P.O. Box 3030, Irbid-22110, Jordan

Fax: + 96227200621

E mail: alghazo@just.edu.jo 